\title{
Friction Characteristics of Liquid Lubricated MEMS with Deterministic Boundary Slippage
}

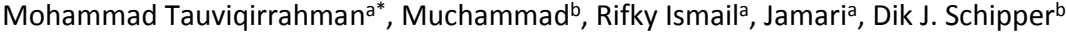 \\ ${ }^{a}$ Department of Mechanical Engineering, University of Diponegoro, Jl. Prof. Soedharto, Tembalang, Semarang, Indonesia \\ ${ }^{b}$ Laboratory for Surface Technology and Tribology, Faculty of Engineering, University of Twente, Drienerloolaan 5, Postbus 217, 7500 AE, Enschede, The \\ Netherlands
}

*Corresponding author: mtauviq99@gmail.com

Article history

Received :18 December 2013

Received in revised form :

11 January 2014

Accepted :25 January 2014

Graphical abstract

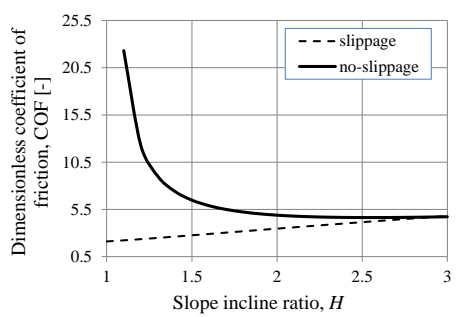

Slope incline ratio, $H$

\begin{abstract}
It has been proven experimentally that boundary slippage represents a viable effect on the hydrodynamic performance of lubricated sliding contacts. Along with several friction reduction mechanisms that have been explored in the literature, the slippage parameters remain an important feature. With the main objective of evaluating the effects of the slippage, a modified Reynolds equation is employed. The result shows that deterministic boundary slippage of the lubricated-MEMS with uniform film thickness has a very beneficial effect on decreasing friction force as well as coefficient of friction.
\end{abstract}

Keywords: Boundary slippage; friction; coefficient of friction; lubrication; micro-electro-mechanicalsystem (MEMS)

\section{Abstrak}

Secara eksperimen telah terbukti bahawa gelinciran sempadan menunjukkan kesan yang lebih baik kepada prestasi pelinciran hidrodinamik. Bersama dengan beberapa mekanisma pengurangan geseran yang telah dilihat dalam kajian lepas, parameter gelinciran kekal sebagai satu ciri yang penting. Objektif utama adalah untuk menilai kesan gelinciran menggunakan persamaan Reynolds yang diubahsuai. Dapatan menunjukkan bahawa gelinciran sempadan-MEMS dengan pembentukkan lapisan ketebalan filem amat berkesan terhadap pengurangan daya geseran dan juga pekali geseran.

Kata kunci: Gelinciran sempadan; geseran, pekali geseran; pelinciran; sistem-mekanikal-mikro-elektro (MEMS)

\subsection{INTRODUCTION}

For the last years, there has been a tremendous effort towards the development of micro-electro-mechanical-system (MEMS) for a wide variety of applications. However, one main factor that limits the widespread development and reliability of MEMS is a high level of friction and wear [1]. Furthermore, every type of MEMS device is susceptible to stiction [2]. Stiction (a subtraction of 'static friction') in micro-system technology has been still a problem which limits the life-time of MEMS devices. As the overall size of a device is reduced, the capillary and surface tension forces of the liquid become large, which induce stiction rendering the devices to fail or malfunction.

Several approaches to address the stiction between two opposing surfaces have been proposed including self-assembled molecular (SAM) coatings, hermetic packaging and the use of reactive materials in the package [3]. Another promising technique to tackle the stiction problem is by using a liquid lubricant between the interacting components of MEMS devices, with high amounts of sliding. However, a significant barrier in the development of MEMS lubrication is the problem of achieving proper tribological performance of their moving parts [4], because the lubricant behavior is different at microscale compared to macro-scale. In the classical lubrication theory, it is well-known that the no-slippage boundary condition, i.e. the fluid is immediately adjacent to a solid surface and moves at the same velocity as the surface, is the core concept [5]. The no-slippage boundary has been employed almost universally at macroscopic level in the fluid mechanics and remains an assumption that is not based on physicals principles. However, with the continuous progress of the measurement techniques during recent years, strong evidence for slippage has been provided by a great number of researchers [6-13]. The evidence of slippage has been generally accepted and for certain cases the no-slippage boundary condition is not valid. In lubricated-MEMS, the no-slippage boundary is generally an unwanted condition because it can lead to the 
occurrence of stiction and as a result the micro-parts cannot move [2].

In liquid lubricated-MEMS, the boundary condition will play a very important role in determining the lubricant flow behavior. A technique of controlling the hydrodynamic friction force is to promote the occurrence of boundary slippage at the surface. In published works [11-15], both experimentally and numerically, it was shown that boundary slippage is able to reduce hydrodynamic friction force at the contacting surfaces. These findings allow the use of liquid lubrication in MEMS become feasible in practice. Further, in recent work [16] the effectiveness of boundary slippage in a deterministic way was investigated with respect to load support. The authors proposed the so-called deterministic boundary slippage surface (DBSS) pattern. The stationary surface was modified in such a way that boundary slippage takes places in the certain region. The deterministic boundary slippage surface predicted the improvement of the load support significantly. This paper focuses on the feasibility of deterministic boundary slippage surface (DBSS) pattern in enhancing the friction characteristics in liquid lubricated MEMS.

\subsection{MATHEMATICAL MODEL}

The classical Reynolds equation that is valid under no-slippage boundary condition can be generalized taking into account boundary slippage. It is then possible, for any film thickness height distributions, to calculate the hydrodynamic pressure and the shear rate distributions. The model of lubrication presented here is based on the fact that slippage of the lubricant will exist at the interface between a lubricant and solid surface in a lubricated sliding contact. Boundary slippage is employed both on the moving and stationary surface, see Figure 1. The lubrication model with slippage leads to a modified Reynolds equation as presented in Equation (1), see Ref. [16] for the derivation. In this study, it should be noted that the occurrence of slippage in a lubricated sliding contact is determined by two criteria. Firstly, slippage may only occur in those areas where both stationary and moving surface have been treated to allow it. Secondly, the shear stress on both surfaces must exceed a critical shear stress value, referred as $\tau_{c a}$ for stationary surface and $\tau_{c b}$ for the moving surface. When both criteria are met the resulting slippage velocity is proportional to the difference between the shear stress and the critical value, with proportionality factors referred to as $\alpha_{a}$ for the stationary surface and $\alpha_{b}$ for the moving surface. It means that each of the surfaces has a unique slippage property. The product of the slippage coefficient with the viscosity, $\alpha \eta$, is commonly named 'slippage length'.

Equation (1) is derived by following the usual approach to deduce the Reynolds equation from the Navier-Stokes system by assuming classical assumptions except that boundary slippage is applied both on the stationary surface and the moving surface as depicted in Figure 1.

$$
\begin{aligned}
& \frac{\partial}{\partial x}\left(h^{3} \frac{h^{2}+4 h \eta\left(\alpha_{a}+\alpha_{b}\right)+12 \eta^{2} \alpha_{a} \alpha_{b}}{h\left(h+\eta\left(\alpha_{a}+\alpha_{b}\right)\right)} \frac{\partial p}{\partial x}\right)=6 \eta U \frac{\partial}{\partial x}\left(\frac{h^{2}+2 h \alpha_{a} \eta}{h+\eta\left(\alpha_{a}+\alpha_{b}\right)}\right) \\
& -6 \eta \tau_{c a} \frac{\partial}{\partial x}\left(\frac{\alpha_{a} h\left(h+2 \alpha_{b} \eta\right)}{h+\eta\left(\alpha_{a}+\alpha_{b}\right)}\right)+6 \eta \tau_{c b} \frac{\partial}{\partial x}\left(\frac{\alpha_{b} h\left(h+2 \alpha_{a} \mu\right)}{h+\eta\left(\alpha_{a}+\alpha_{b}\right)}\right)-12 \eta U \frac{\alpha_{a} \eta}{h+\eta\left(\alpha_{a}+\alpha_{b}\right)} \frac{\partial h}{\partial x} \\
& \frac{\partial}{\partial x}\left(h^{3} \frac{h^{2}+4 h \eta\left(\alpha_{a}+\alpha_{b}\right)+12 \eta^{2} \alpha_{a} \alpha_{b}}{h\left(h+\eta\left(\alpha_{a}+\alpha_{b}\right)\right)} \frac{\partial p}{\partial x}\right)=6 \eta U \frac{\partial}{\partial x}\left(\frac{h^{2}+2 h \alpha_{a} \eta}{h+\eta\left(\alpha_{a}+\alpha_{b}\right)}\right)
\end{aligned}
$$

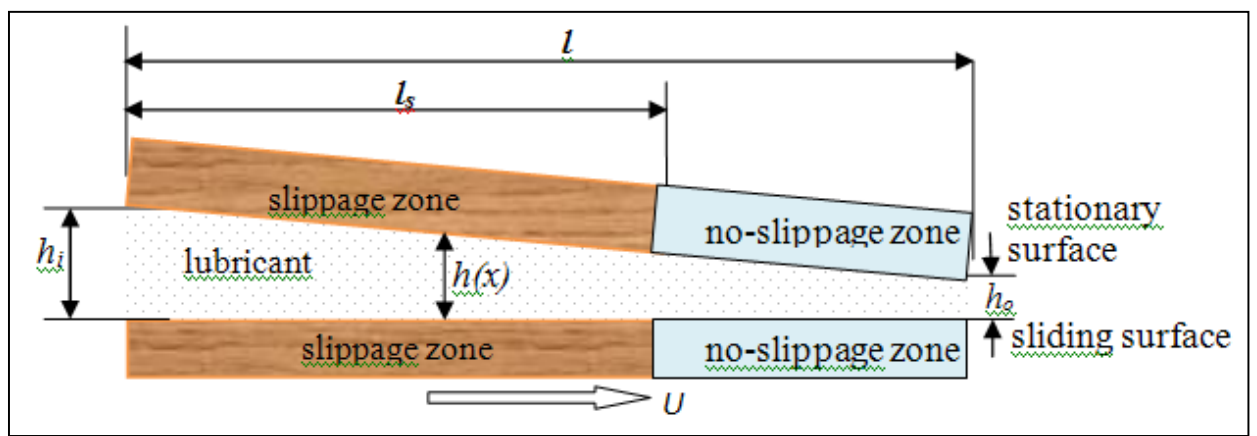

Figure 1 Schematic representation of liquid lubricated sliding MEMS contact with deterministic boundary slippage

\subsection{NUMERICAL PROCEDURE}

The modified Reynolds equation, Equation (1) is solved numerically using finite difference equations obtained by means of the micro-control volume approach and using the Tridiagonal-Matrix-Algorithm (TDMA), [17]. By employing the discretization scheme, the computed domain is divided into a number of control volumes using a grid with uniform mesh size which is applied to the slippage region. 101 meshes are employed in the computational domain. The grid independency is validated by changing the mesh size. If the mesh number was above 101, the simulation results did not differ anymore. But obviously the computational cost increased. 
To investigate the effect of boundary slippage characteristics on the lubrication performance of sliding surfaces, various parameters are set. The primary parameters for all following computations are given as follows: sliding velocity $U$ is $1 \mathrm{~m} / \mathrm{s}$ (the corresponding Reynolds number $R e$ is 1 assuming the fluid density is $1,000 \mathrm{~kg} / \mathrm{m}^{3}$ and the dynamic viscosity $\eta$ is 0.001 Pa.s), the total length of the lubricated contact $l$ is $20 \times 10^{-3} \mathrm{~m}$ and the outlet film thickness $h_{o}$ is $1 \times 10^{-6} \mathrm{~m}$. In the following simulations, the slippage coefficient $\alpha$ varies from 0 to 0.05 $\mathrm{m}^{2} \mathrm{~s} / \mathrm{kg}$ based on the results published in literature $[11,12,15,18]$. All parameters and the range in which they are varied are summarized in Table 1. An assumption is made that the boundary pressures are zero at both sides of the contact. In the present study, Reynolds boundary cavitation condition is modeled. It consists in ensuring that $p=0$ and $\partial p / \partial x=0$ at the rupture limits of the lubricant film. The most important parameters such as dimensionless slippage length $B$ (where $B=$ $\left.\eta \alpha / h_{o}\right)$ and slope incline ratio $H$ (where $H=h_{i} / h_{o}$ ) are examined in detail.

Table 1 Simulated parameters

\begin{tabular}{lll}
\hline Parameter & Data setting & Unit \\
& & \\
\hline Slip coefficient, $\alpha$ & $0-0.05$ & $\mathrm{~m}^{2} . \mathrm{s} / \mathrm{kg}$ \\
Slope incline ratio, & $1-3$ & {$[-]$} \\
$H$ & & \\
\hline
\end{tabular}

\subsection{RESULTS}

\subsection{Effect of Slope Incline Ratio}

The hydrodynamic viscous friction force is a good measure for determining the effectiveness of the deterministic boundary slippage. The friction force of a lubrication film can be achieved by integrating the shear stress over the surface area. The simulation results will be presented in dimensionless form, i.e. $F$ $=f h_{o} /(U \eta l)$ for dimensionless friction force in which $f$ is friction force per unit width, and $T_{x z}=\tau_{x z} h_{o} /(U \eta)$ for dimensionless local shear stress.

Previous research [16] demonstrated that a deterministic boundary slippage surface (DBSS) is superior to a homogeneous slippage surface as well as no-slippage surface with respect to load support. The DBSS pattern is generally most effective with respect to the maximum load support if (1) the length of the slippage zone $l_{s}$ of deterministic boundary slippage surface (DBSS) covers 0.65 of the contact length $l$ at the leading edge of the contact, see Figure 1, (2) the critical shear stress $\tau_{c}$ is zero, and/or (3) slippage is applied only on the stationary surface. In the present study, in order to show the benefit of the use of a DBSS pattern, all slippage profiles are compared with the noslippage distribution at the optimized slope incline ratio $H$ of 2.2. From the analytical solution described in Ref. [19], it is known that at $H$ of 2.2, the hydrodynamic pressure has the highest value. In the following computations, the DBSS properties $l_{s} / l=0.65$ and $\tau_{c}=0$ are employed on the stationary surface.

Figure 2 shows the dimensionless surface shear stress distribution $T_{x z}$ for different values of several slope incline ratio $H$ as a function of dimensionless coordinate $x / l$. It can be seen that for all $H$, the dimensionless shear stress distribution is mainly higher in the region of slippage, compared to the contact region with no slippage surface, but decreases considerably in the region of no slippage, compared to the contact region with no slippage surface. As is shown in Figure 3, when $H=1$ (i.e. parallel sliding surfaces), the minimum dimensionless friction force is highlighted. This finding is very beneficial with respect to the tribological performance, because as discussed in Ref [16], the optimized DBSS pattern (i.e. $l_{s} / l=0.65$ ) with parallel sliding surfaces gives the highest load support. From Figure 3, it is also found that when compared with the no slippage case at the same $H$, the friction force predicted by DBSS pattern is much lower especially for very low $H$. This is to say, that in addition to the improvement of the load support [16], the use of DBSS pattern is also effective for reducing the friction force even the absence of the wedge effect (i.e. parallel sliding surfaces).

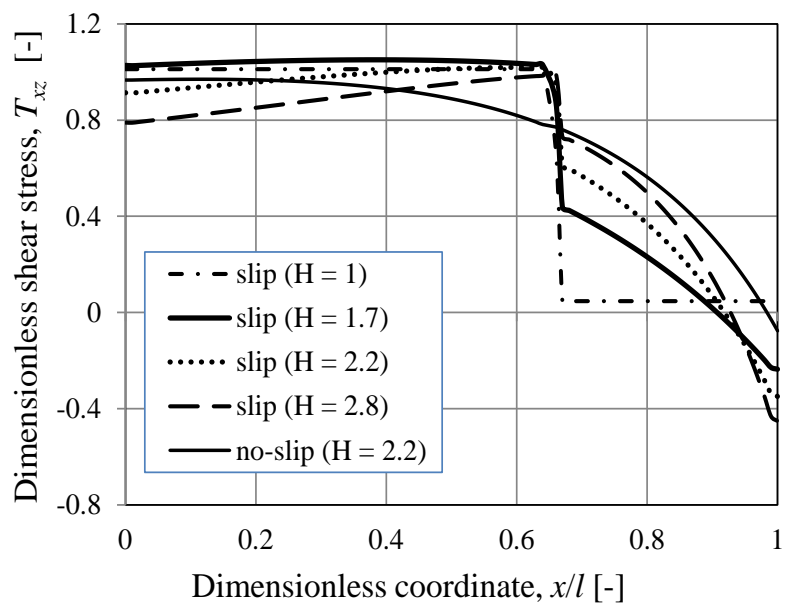

Figure 2 Distribution of dimensionless shear stress, $T_{x z}$ for several slope incline ratio, $H$. All slippage profiles are calculated for dimensionless slippage length, $B$ of 20

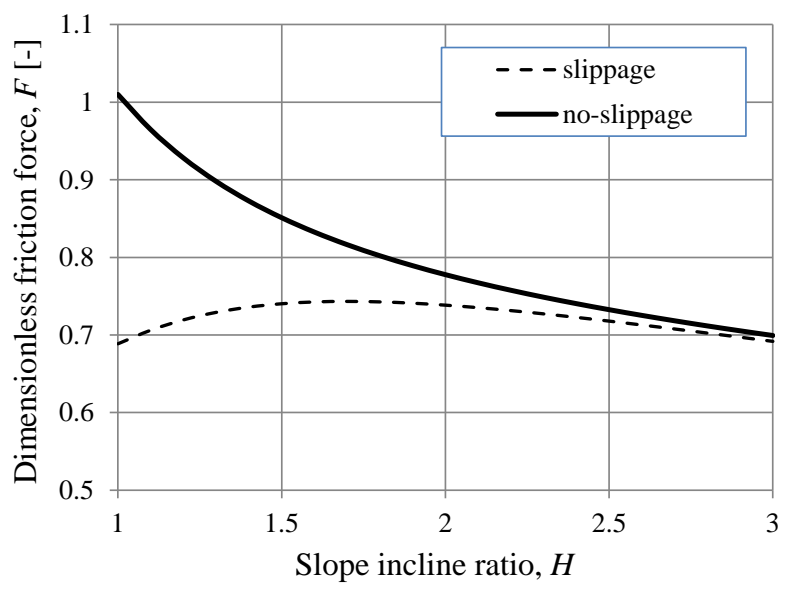

Figure 3 Dimensionless friction force, $F$ as a function of the slope incline ratio, $H$. Slippage profile is calculated for dimensionless slippage length $B$ of 20

As reported by other researchers, when the lubricant slips along the solid-liquid interface, a large slippage is also related with large friction force reduction. However, in real practice, in addition to the influence of the friction force reduction, at the same time, the slippage may decrease the hydrodynamic pressure and thus the load carrying capacity. However, in MEMS, by lubrication, a high load carrying capacity, as well as a low friction force is wanted. Therefore, the deterministic 
slippage effect on hydrodynamic effect can be better analyzed using the dimensionless coefficient of friction. In the present work, the dimensionless coefficient of friction, $\mathrm{COF}$ is obtained by normalizing the dimensionless friction force with the dimensionless load carrying capacity.

Figure 4 show how the coefficient of friction, $\mathrm{COF}$ varies with slope incline ratio. The results are evaluated for different condition, i.e. with and without boundary slippage. In the case of no-slippage lubricated surface, it is observed that the higher the value of the slope incline ration, the lower the coefficient of friction. Specifically, for $H$ lower than 2.2, the increase in $H$ leads to a large decrease in the COF of the lubricated contact, whereas for $H$ greater than say 2.2, the variation in $H$ has a less effect on the performance.

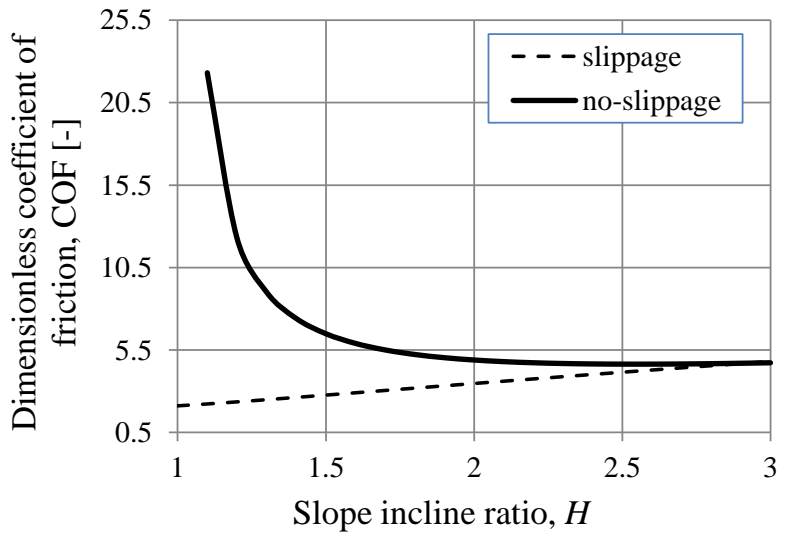

Figure 4 Dimensionless coefficient of friction, COF versus slope incline ratio, $H$. Slippage profile is calculated for dimensionless slippage length $B$ of 20

As can be seen in Figure 4, in the case of the lubricated sliding contact with deterministic boundary slippage, there is the strikingly large reduction in coefficient of friction at low slope incline ratio. The lowest coefficient of friction is highlighted when parallel sliding contact is employed. It is interesting to observe that for no-slippage contact, when $H=1$, the COF has an infinite value (not shown in Figure 4). This is due to the fact that there is no load carrying capacity when parallel sliding contact is used. As can be seen in Figure 4, the coefficient of friction rises continuously with increases of slope incline ratio, to reach the classical Reynolds value when there is no slip over the whole top surface. It means that the optimized slippage contact behaves like a traditional one (without slippage). Again, the numerical results show that adding the deterministic boundary slippage to the lubricated contact with uniform film thickness is preferable.

\subsection{Effect of Slippage Length}

Numerous researches have performed that a chemical modification of the surface produces a slippage length in the order of $1 \mu \mathrm{m}$ [22], while a greater slippage length up to $100 \mu \mathrm{m}$ can be generated through a combination of a hydrophobic material with an deterministic rough pattern [12,18,22,23]. It is often postulated that a large value of slippage length implies larger slippage. Therefore, the effect of wettability (represented by the slippage length in this case) is also of particular interest.

In the previous section (see Figures. 2-4), all slippage profiles are presented using the dimensionless slippage length $B$ of 20. Therefore, the issue of how does the dimensionless slippage length affect the friction force for the DBSS pattern will be explored in this section. The variation of the dimensionless friction force $F$ as a function of the dimensionless slippage length $B$ for various slope incline ratio values $H$ is shown in Figure 5. Generally, for all $H$ it appears that dimensionless friction force will decrease with an increase in the dimensionless slippage length $B$, especially for small $B$. However, only for cases with high $H(H>2.2)$, a significant friction reduction is not found. For example, for the DBSS pattern subject to a dimensionless slippage length of 50, the friction force differs from the no-slippage surface (i.e. when $B=$ 0 ) by only $1.3 \%$ (lower). As the slope incline ratio is decreased to 1 (i.e. parallel sliding surfaces), the discrepancies in friction force increases (at a dimensionless slippage length of 50, it is up $32 \%$ ). It means that the beneficial effect of DBSS will vanish with respect to friction due to the wedge effect $(d h / d x)$. This result, again, strengthens the previous finding (see Figure 3) which mentioned that only when the wedge effect is absent (i.e. $H=1$ ), the friction reaches a minimum value and this is the most wanted effect in lubricated MEMS.

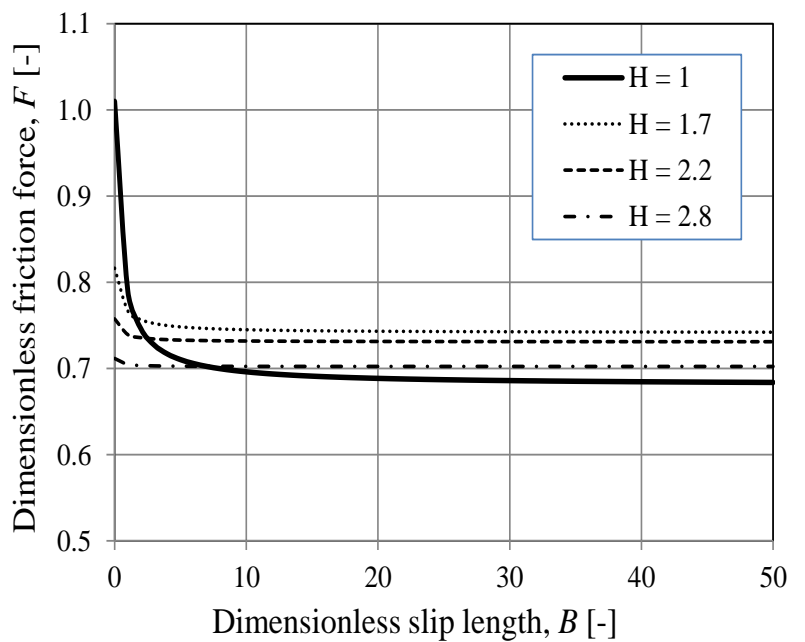

Figure 5 Dimensionless friction force, $F$ as a function of dimensionless slippage length, $B$ with different values of slope incline ratio, $H$

Inspection of Figure 5 shows that in the case of parallel sliding surface $(H=1)$, when the dimensionless slippage length $B$ is smaller than 10 , the friction decreases significantly. The reduction in hydrodynamic friction has mainly been attributed to the decrease in the shear stress distribution in the no slippage region with the increase of slippage length (see Figure 6). It can also be deduced from Figure 5 that after $B=10$, increasing the slippage zone will be less effective to reduce friction. Here, the dimensionless slippage length $B$ of 10 can be considered as an optimal value for generating a perfect slippage effect in the lubricated sliding contacts. However, for a higher value of $H$ (for example $H=2.8$ ), there is a shift of the optimum dimensionless slippage length towards the $B$ value which is smaller than the optimum of $B$ for the case of $H=1$, i.e somewhere between $B=1$ and $B=3$. It indicates that there is a threshold value of the dimensionless slippage length which is unique for each slope incline ratio. In general, however, the best characteristic performance can be achieved when the configuration of the DBSS pattern has a high slippage length. This is as expected because a large value of slippage length implies larger boundary slippage. This has also been confirmed in recent literature $[20,21]$. 
In relation to the coefficient of friction, as can be seen in Figure 7, at a low slope incline ratio ( $H \leq 1.7$ ) for dimensionless slip length lower than - for example - 10, the increase in $B$ leads to a large decrease in the dimensionless coefficient of friction of the lubricated sliding contact, whereas for $B$ greater than 10 , the variation in $B$ has an insignificant effect on the performance. It can also be noted that when slope incline ratio is increased, the benefit of employing deterministic slippage on the lubricated surface will vanish. The prediction will be similar to that of noslippage situation. Again, this result is consistent with the previous result that states that the optimal values of slippage length are noted. These values are identical for lubricated contact both for high and low slope incline ratio.

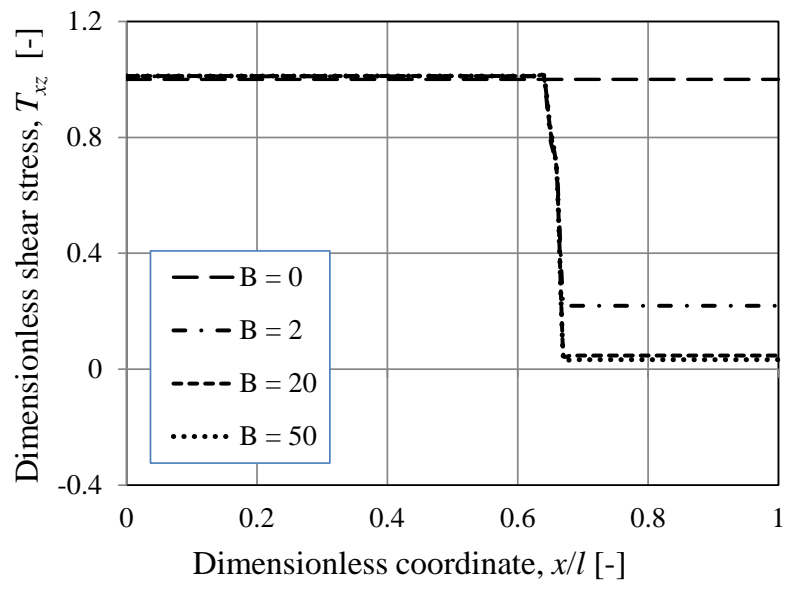

Figure 6 Distribution of dimensionless shear stress $T_{x z}$ for several dimensionless slippage lengths $B$ in the case of parallel sliding surfaces $(H=1)$

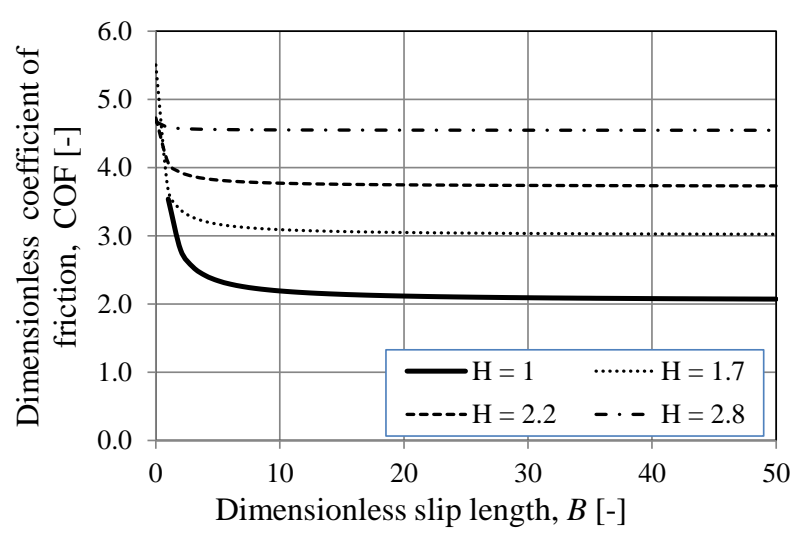

Figure 7 Dimensionless coefficient of friction, $\mathrm{COF}$ versus dimensionless slippage length, $B$ for various values of slope incline ratio, $H$

\subsection{DISCUSSION}

In a real system, for example in lubricated-MEMS containing moving surfaces, the deterministic boundary slippage surface (DBSS) pattern can be a promising way for increasing the load support and reducing the friction. Because a DBSS pattern is relatively easy to obtain, the DBSS pattern for increased-MEMS performance by lubrication may be more applicable. If compared to the use of texturing which needs the technology of texturing (for instance using a laser), the slippage zone can be obtained by grafting or by the deposition of hydrophobic compounds to the initial surfaces. These technical procedures can lead to a modification of the surface energy [24], i.e. wettability.

According to the classical Reynolds theory, a convergent geometrical wedge is one of the most important conditions to generate hydrodynamic pressure. In this paper, it is shown that (slightly) parallel moving surfaces with an optimized complex slip surface, can also provide a fluid load carrying capacity. This finding is similar to the result of lubricated sliding contact analysis by $\mathrm{Wu}$ et al. [25].

The DBSS pattern may consist of the combination of two surface types, i.e. hydrophilic and hydrophobic. They can lead to a method to control boundary slippage. A (super) hydrophobic surface shows boundary slippage compared to hydrophilic surfaces. For most hydrophilic surfaces, no-slippage occurs [25]. As is well-known, MEMS technology frequently exhibits parallel moving surfaces. In such a surface, with a homogeneous slippage and/or no-slippage condition, no load support takes place $[15,16]$. Based on the numerical simulations presented here, even in the absence of the wedge effect, it was shown that an optimized deterministic boundary slippage surface (DBSS) pattern leads to better performance in terms of friction reduction.

\subsection{CONCLUSION}

In the present study, numerical efforts of exploring boundary slippage in a deterministic way (i.e. deterministic boundary slippage surface (DBSS) pattern) in obtaining a low friction were of particular interest. The modified Reynolds equation has been used to evaluate the effects of DBSS pattern in lubricatedMEMS. The results indicated that the deterministic deterministic boundary slippage pattern has a beneficial effect by decreasing the friction. Practical recommendation on the importance of the well-chosen operational parameter was given. The best characteristic performance (i.e. friction force reduction, as well as coefficient of friction) can be achieved when the configuration of the lubricated-MEMS has a high slippage length and low slope incline ratio. This finding may have useful implications for reducing the stiction and thus increasing the life time of in liquid-lubricated-MEMS devices.

\section{References}

[1] Henck, S. A. 1997. Lubrication of Digital Micromirror Devices. Tribology Letters. 3: 239.

[2] Israelachvili J. 1995. Intermolecular and Surface Force vol. 1. 2nd Edition. Academic Press, London.

[3] van Spengen, W. M., Puers, R., De Wolf. 2003. On the Physics of Stiction and Its Impact on the Reliability of Microstructures. Journal of Adhesion Science and Technology. 17: 563.

[4] Spearing, S. M. 2000. Materials Issues in Microelectroctromechanicalsystems (MEMS). Acta Materialia. 48: 179

[5] Hamrock, B. J. 1994. Fundamentals of Fluid Film Lubrication McGraw-Hill, In. New York.

[6] Zhu, Y., Granick, S. 2001. Rate Dependent Slip of Newtonian Liquid at Smooth Surfaces. Physical Review Letters. 87: 096105.

[7] Spikes, H. A., Granick, S. 2003. Equation for Slip of Simple Liquids at Smooth Solid Surfaces. Langmuir. 19: 5065.

[8] Zhu, Y., Granick, S. 2002. Limits of Hydrodynamic No-Slip Boundary Condition. Physical Review Letters. 88: 106102.

[9] Hild, W., Opitz, A., Schaefer, J. A., Scherge, M. 2003. The Effect of Wetting on the Microhydrodynamics of Surfaces Lubricated With Water and Oil. Wear. 254: 871 .

[10] Cheng, J.-T., Giordano, N. 2002. Fluid Flow Through NanometerScale Channels. Physical Review E. 65: 031206. 
[11] Choo, J. H., Spikes, H. A., Ratoi, M., Glovnea, R., Forrest, A. 2007. Friction Reduction in Low-load Hydrodynamic Lubrication with a Hydrophobic Surface. Tribology International. 40: 154.

[12] Choo, J. H., Glovnea, R. P., Forrest, A. K, Spikes, H. A. 2007. A Low Friction Bearing Based on Liquid Slip at the Wall. ASME Journal of Tribology. 129: 611.

[13] Leong, J. Y., Reddyhoff, T., Sinha, S. K., Holmes, A. S., Spikes, H. A. 2013. Hydrodynamic Friction Reduction in a MAC-Hexadecane Lubricated MEMS Contact. Tribology Letters. 49: 217.

[14] Spikes, H. A. 2003. The Half-Wetted Bearing. Part 1: Extended Reynolds Equation, Proceedings of the Institution of Mechanical Engineers, Part J. Journal of Engineering Tribology. 217: 1.

[15] Salant, R. F., Fortier, A. E. 2004. Numerical Analysis of a Slider Bearing with a Heterogeneous Slip/No-Slip Surface. Tribology Transactions. 47: 328.

[16] Tauviqirrahman, M., Ismail, R., Jamari, J., Schipper, D. J. 2013. Study of Surface Texturing and Boundary Slip on Improving the Load Support of Lubricated Sliding Contacts. Acta Mechanica. 224: 365.

[17] Patankar, S. V. 1980. Numerical Heat Transfer and Fluid Flow. Taylor \& Francis, Levittown.

[18] Watanabe, K., Yanuar, Udagawa, H. 1999. Drag Reduction of Newtonian Fluid in a Circular Pipe with a Highly Water-Repellent Wall. Journal of Fluid Mechanics. 381: 225.
[19] Cameron, A. 1966. The Principles of Lubrication. Longman Green and Co,Ltd, London.

[20] Rao, T. V. V. L. N., Rani, A. M. A., Nagarajan, T., Hashim, F. M. 2012. Analysis of Slider and Journal Bearing using Partially Textured Slip Surface. Tribology International. 56: 121.

[21] Wang, L. L., Lu, C. H., Wang, M., Fu, W. X. 2012. The Numerical Analysis of the Radial Sleeve Bearing with Combined Surface Slip. Tribology International. 47: 100.

[22] Tretheway, D. C. Meinhart, C. D. 2002. Apparent Fluid Slip at Hydrophobic Microchannel Walls. Physics of Fluids. 14: L9-12.

[23] Ou, J., Perot, B., Rothstein, J. P. 2004. Laminar Drag Reduction in Microchannels using Ultrahydrophobic Surfaces. Physics of Fluids. 16: 4635.

[24] Aurelian, F., Patrick, M., Mohamed, H. 2011. Wall Slip Effects in (Elasto) Hydrodynamic Journal Bearing. Tribology International. 44: 868.

[25] Wu, C. W., Ma, G. J., Zhou, P. 2006. Low Friction and High Load Support Capacity of Slider Bearing with a Mixed Slip Surface. ASME Journal of Tribology. 128: 904. 